\title{
Isolation of Lipoteichoic Acids from Butyrivibrio fibrisolvens
}

\author{
By MERILYN J. HEWETT AND A. J. WICKEN \\ School of Microbiology, University of New South Wales, Kensington, \\ N.S.W. 2033, Australia \\ K. W. KNOX \\ Institute of Dental Research, United Dental Hospital, Sydney, N.S.W. 2010, Australia \\ AND M. ELISABETH SHARPE \\ National Institute for Research in Dairying, Shinfield, Reading RG2 9AT, Berkshire
}

(Received 30 October 1975)

\begin{abstract}
SUMMARY
Lipoteichoic acid (LTA) and deacylated lipoteichoic acid have been isolated from the bovine-rumen Gram-negative anaerobe Butyrivibrio fibrisolvens by phenol extraction. Lipoteichoic acid (2I.8 $\mu \mathrm{mol}$ phosphorus/g cells) consisted of a conventional 1,3-phosphodiester-linked chain of glycerol phosphate units joined covalently to a glycolipid. It was not substituted with glycosyl or D-alanyl ester groups. Deacylated lipoteichoic acid $(57.5 \mu \mathrm{mol}$ phosphorus/g cells) was similar in constitution but lacked fatty acid esters. Lipoteichoic acid reacted serologically with antisera to the glycerol phosphate backbone of known lipoteichoic acids. The presence of similar teichoic acid polymers has also been demonstrated in some other strains of $B$. fibrisolvens and this is of significance in demonstrating that teichoic acids can occur in Gram-negative bacteria.
\end{abstract}

\section{INTRODUCTION}

Teichoic acids have generally been considered as uniquely Gram-positive bacterial components and, in the form of membrane lipoteichoic acids (LTA), are common to practically all Gram-positive bacteria (Wicken \& Knox, 1975). The use of specific antisera to the common polyglycerol phosphate backbone of lipoteichoic acids has made it easy to detect this antigenic determinant in extracts of a wide range of Gram-positive bacteria (Sharpe et al., 1973; Wicken \& Knox, 1975). Recently it has been reported that extracts of some strains of the Gram-negative rumen anaerobe, Butyrivibrio fibrisolvens, show a strong positive serological reaction for the polyglycerophosphate antigenic determinant: material which had chemical degradation products typical of glycerol teichoic acids and gave specific serological reactions with antisera to the polyglycerophosphate backbone, was isolated in very low yield - of the order of $0.02 \%$ dry wt of the cells - from strain Nor 37 (Sharpe, Brock \& Phillips, I975a). This was the first evidence for the hitherto unreported occurrence of teichoic acids in Gram-negative bacteria.

This paper describes the isolation, by conventional procedures, and partial characterization of lipoteichoic acid from strain Nor37; and indicates that similar polymers are present in some other strains of $\boldsymbol{B}$. fibrisolvens. Some of these results were reported in a preliminary communication (Sharpe et al., 1975b). 


\section{METHODS}

Strains. Three strains of B. fibrisolvens (Nor37, IL6-3 I and 49), which showed a positive serological reaction for polyglycerophosphate, and two strains (DI and 7A), which did not react with antisera to polyglycerophosphate (Sharpe et al., 1975a), were chosen.

Cultivation. Bacteria were cultured using strictly anaerobic techniques (Bryant \& Robinson, I96I) in a modified medium Mio (Caldwell \& Bryant, I966) containing ( $\%$,w/v): yeast extract, 0.4 ; acetic acid, 0.06; glucose, 0.5 ; and Trypticase (BBL), mineral solutions I and $\mathrm{II}$, resazurin, cysteine- $\mathrm{HCl}$ and sodium carbonate in the same concentrations as originally described. To obtain a suitable cell mass, each strain was grown in three 51 portions of medium to which the glucose had been added as a separate sterile solution after autoclaving. Each 51 portion was inoculated with $10 \mathrm{ml}$ of overnight culture and gassed continuously with $\mathrm{CO}_{2}$ during $20 \mathrm{~h}$ incubation at $39{ }^{\circ} \mathrm{C}$. Microscopic examination of stained preparations showed the cultures to be uniformly Gram-negative. Bacterial cells were harvested by centrifuging at $21000 \mathrm{~g}$, and lyophilized.

Yields of bacterial cells (g dry wt/I 51 culture) were: Nor37, I2·0; IL6-3I, II·8; 49, 5.2; DI, II $0 ; 7 \mathrm{~A}, 4 \cdot 0$.

Extraction and purification of lipoteichoic acids. Freeze-dried organisms were suspended in distilled water and extracted with hot aqueous $90 \%(\mathrm{w} / \mathrm{v})$ phenol as previously described (Wicken, Gibbens \& Knox, 1973). Dialysed aqueous-phase extracts were fractionated on columns of $6 \%$ agarose or Sephadex G75 and monitored for organic phosphorus, and extinction at $280 \mathrm{~nm}$.

Chemical and serological methods. All chemical, chromatographic, analytical and serological procedures were as detailed in previous publications (Knox, Hewett \& Wicken, 1970; Knox \& Wicken, 1970; Knox \& Wicken, 1972; Wicken et al., 1973; Wicken \& Knox, 1970; Wicken \& Knox, 1971).

\section{RESULTS AND DISCUSSION}

Fractionation of the aqueous phase of hot phenol extracts of $B$. fibrisolvens Nor37 on columns of $6 \%$ agarose yielded two peaks of material containing organic phosphorus. The higher molecular weight fraction (I) contained $2 \mathrm{I} \cdot 8 \mu \mathrm{mol}$ phosphorus $/ \mathrm{g}$ dry wt of organisms and the lower molecular weight fraction (II) contained $57.5 \mu \mathrm{mol}$ phosphorus/g dry wt organisms. The elution volumes of fractions I and II corresponded closely to those of LTA and deacylated LTA, respectively, extracted by the same procedure from other organisms (Knox \& Wicken, 1973; Markham et al., 1975). Preparations of fractions I and II contained varying amounts of protein. Fraction II was also contaminated with nucleic acid material, but this was reduced to less than $\mathrm{x} \%(\mathrm{w} / \mathrm{w})$ by further chromatography on Sephadex $\mathrm{G}_{75}$.

Acid degradation of fractions I and II produced glycerol and its mono- and di-phosphates together with small amounts of glucose and a range of fatty acids from fraction I. Both fractions were completely hydrolysed in alkali to a mixture of glycerol, glycerol mono- and di-phosphates and small amounts of diglycerol triphosphate. The latter product was characterized by converting it with alkaline phosphomonoesterase to diglycerol phosphate [ $R_{\text {glycerol }}$ was 0.70 in n-propanol-ammonia $(d=0.88)-\mathrm{H}_{2} \mathrm{O} ; 6: 3: \mathrm{I}$, by vol.]: this has a characteristic fast reaction with the periodate + Schiff's chromatographic spray reagent, and was further hydrolysed in alkali to glycerol and glycerol phosphate. Such an hydrolysis pattern is indicative of a conventional 1,3-phosphodiester-linked polymer of glycerol phosphate units. Phosphomonoesterase digestion of a total alkali hydrolysate of either 
fraction failed to yield detectable quantities of 2-substituted glycerol glycosides. However, small quantities of a glycoside having a fast reaction with the periodate + Schiff's reagent, which indicates a I-substituted glycerol glycoside, were detected in alkali hydrolysates of both fractions. Acid hydrolysis of this material yielded glucose and glycerol only and the low chromatographic mobility of the glycoside $\left(R_{\text {glocose }}\right.$ was 0.35 in n-butanol-pyridinewater; $6: 4: 3$, by vol.) suggests that it is possibly a trisaccharide-substituted glycerol. Esterlinked D-alanine was not detected in either fraction and ammonolysis failed to release significant quantities of ninhydrin-reactive material from either polymer. Quantitative analyses of several preparations of fractions I and II showed molar ratios of phosphorus: glucose varying between $1 \cdot 00: 0 \cdot 02$ and $1 \cdot 00: 0 \cdot 04$. The absence of any sugar other than glucose in acid hydrolysates of these preparations indicates the absence of a conventional lipopolysaccharide in phenol extracts of strain Nor37.

These findings are consistent with fraction I being a conventional LTA having an unsubstituted I,3-phosphodiester-linked polyglycerophosphate chain linked to a glycosyl-Iglyceride, and fraction II being a non-micellar and lower molecular weight deacylated form of fraction I. The presence of two forms of LTA in extracts of other bacteria, as well as in the external media used for their growth, has been reported (Markham et al., 1975; Wicken \& Knox, 1975; Joseph \& Shockman, 1975). In these latter studies, the existence of deacylated LTA does not appear to be an artefact of the extraction procedures employed but rather it is related to the excretion of LTA in a deacylated form. The total amount of teichoic acid phosphorus extracted from strain Nor37 is comparable to that found in Gram-positive organisms and is some 50 to 100 times greater than the amount previously isolated from this strain (Sharpe et al. 1975a). This previously isolated material probably relates to fraction II, fully acylated LTA being expected to be largely retained by two passages through columns of DEAE-cellulose (Knox \& Wicken, 1973). The material obtained by Sharpe et al. (1975a) also had a low glucose content (molar ratio phosphorus:glucose, $\mathrm{I}: 0.08$ ) and was almost devoid of ester-linked amino acids.

Extracts of $B$. fibrisolvens 1L6-3 I gave essentially similar results. Lipoteichoic acid and deacylated LTA fractions showed identical degradation products to those from strain Nor 37 . Phenol extraction of strain 49 also yielded two organic phosphorus-containing fractions from $6 \%$ agarose columns. Both fractions were contaminated with polysaccharide material, and were not characterized further other than to demonstrate the presence of typical glycerol teichoic acid degradation products in acid hydrolysates. Extracts of strains DI and 7A, which did not react with anti-polyglycerol phosphate antisera, did not show any LTA or deacylated LTA on subsequent chromatography.

Fraction I (LTA) from B. fibrisolvens Nor37 was further characterized serologically. The reaction between Nor37 LTA and antiserum (217) to Lactobacillus casei NCTC6375 LTA, which also lacks 2-glycosyl substituents (Wicken \& Knox, 1975), is shown in Fig. I: $95 \%$ of the antibody precipitated in the homologous reaction was precipitated by Nor 37 LTA. The reaction between Nor 37 LTA and serum 217 was also strongly inhibited by triglycerol diphosphate (Fig. 2), which indicates that the antiserum reacts with the polyglycerophosphate backbone of the polymer, and glycerol phosphate units in the LTA are joined by I,3-phosphodiester linkages (Wicken \& Knox, 1971). Injection of Nor37 LTA into rabbits in Freund's complete adjuvant gave only weakly reacting sera ( $0.3 \mathrm{mg}$ precipitating antibody $/ \mathrm{ml}$ serum), the specificity of which did not appear to be directed at the backbone of the polymer in that the presence of $2 \mu \mathrm{mol}$ triglycerol diphosphate failed to inhibit the reaction between $50 \mu \mathrm{g}$ LTA and $0.4 \mathrm{ml}$ serum.

This study confirms the earlier observations that glycerol teichoic acids are present in 


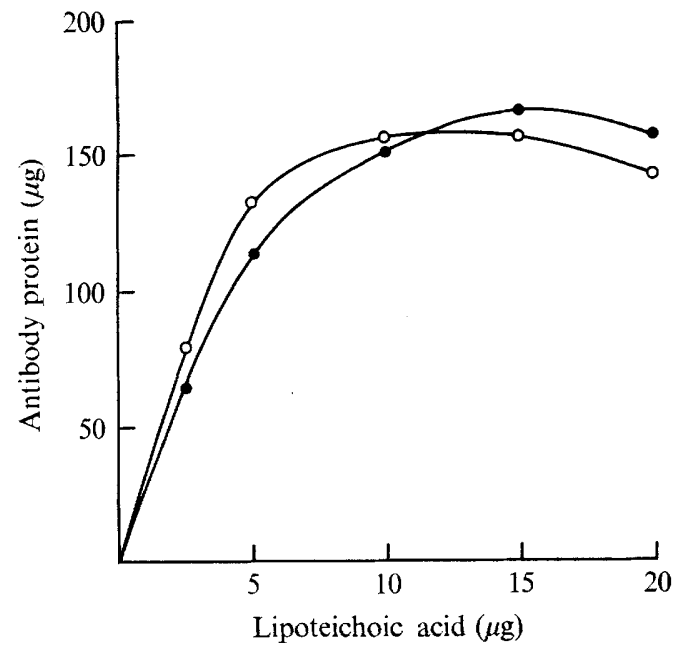

Fig. I

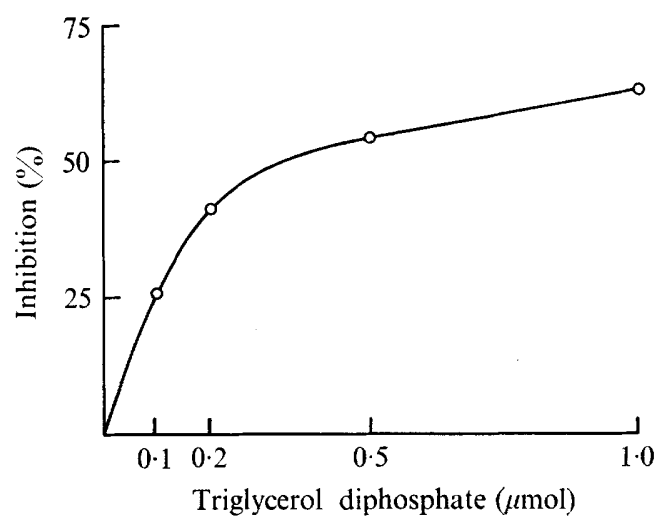

Fig. 2

Fig. 1. Precipitation of lipoteichoic acids from B. fibrisolvens Nor37 ( $)$ and Lactobacillus casei NCTC6375 (O) by antiserum 217 (O.1 $\mathrm{ml})$ to $L$. casei lipoteichoic acid.

Fig. 2. Inhibition of the precipitin reaction between $B$. fibrisolvens Nor37 lipoteichoic acid (Io $\mu \mathrm{g}$ ) and antiserum $217(0.1 \mathrm{ml})$ by triglycerol diphosphate.

some strains of $B$. fibrisolvens (Sharpe et al., 1975a). It also shows that in this Gram-negative genus, apart from the lack of alanine substituents, teichoic acid can occur as a conventional LTA, as well as in the deacylated form, in amounts comparable to that found in most Gram-positive bacteria.

This work was supported by grants to A. J. Wicken and K. W. Knox from the National Health and Medical Research Council of Australia. The competent technical assistance of B. A. Phillips is acknowledged.

\section{REFERENCES}

BRYANT, M. P. \& RoBINSON, I. M. (196I). An improved nonselective culture medium for ruminal bacteria and its use in determining diurnal variation in numbers of bacteria in the rumen. Journal of Dairy Science 44, 1446-1456.

CALDWELL, D. R. \& BRYANT, M. P. (1966). Medium without rumen fluid for nonselective enumeration and isolation of rumen bacteria. Applied Microbiology 14, 794-801.

JosePH, R. \& SHOCKMAN, G. D. (1975). Synthesis and excretion of glycerol teichoic acid during growth of two streptococcal species. Infection and Immunity 12, 333-338.

Knox, K. W., Hewett, M. J. \& Wicken, A. J. (1970). Studies on the group F antigen of lactobacilli. Antigenicity and serological specificity of teichoic acid preparations. Journal of General Microbiology 6o, 303-313.

KNox, K. W. \& WICKEN, A. J. (1970). Serological properties of the wall and membrane teichoic acids from Lactobacillus helveticus NCIB8025. Journal of General Microbiology 63, 237-248.

KNox, K. W. \& WICKEN, A. J. (1972). Serological studies on the teichoic acids of Lactobacillus plantarum. Infection and Immunity 6, 43-49.

KNox, K. W. \& WICKEN, A. J. (I973). Immunological properties of teichoic acids. Bacteriological Reviews $37,215-257$.

Markham, J. L., Knox, K. W., Wicken, A. J. \& Hewett, M. J. (I975). Formation of extracellular lipoteichoic acid by oral streptococci and lactobacilli. Infection and Immunity 12, 378-386.

Sharpe, M. E., Brock, J. H. \& Phillips, B. A. (I975a). Glycerol teichoic acid as an antigenic determinant in a Gram-negative bacterium Butyrivibrio fibrisolvens. Journal of General Microbiology 88, 355-363.

Sharpe, M. E., Brock, J. H., Wicken, A. J. \& KNOX, K. W. (1973). Glycerol teichoic acid as a common antigenic factor in lactobacilli and some other Gram-positive organisms. Journal of General Microbiology 74, I19-1 26. 
Sharpe, M. E., Brock, J. H., Wicken, A. J. \& Knox, K. W. (1975b). Proceedings of the 75th Annual Meeting, Abstract KI I8. New York: American Society for Microbiology.

Wicken, A. J., Gibbens, J. W. \& Knox, K. W. (1973). Comparative studies on the isolation of membrane lipoteichoic acid from Lactobacillus fermenti. Journal of Bacteriology 113, 365-372.

WICKEN, A. J. \& KNOX, K. W. (1970). Studies on the group F antigen of lactobacilli: isolation of a teichoic acid-lipid complex from Lactobacillus fermenti NCTC699. Journal of General Microbiology 60, 293-30I.

WiCKen, A. J. \& KNOX, K. W. (197I). Serological comparison of the membrane teichoic acids from lactobacilli of different serological groups. Journal of General Microbiology 67, 25I-254.

WiCKeN, A. J. \& KNOX, K. W. (1975). Lipoteichoic acids: a new class of bacterial antigen. Science, New York 187 , I I 6I-I I67. 